\title{
LET'S GO GIRLS!: EVALUATING THE EFFECTIVENESS OF TUTORING AND SCHOLARSHIPS ON PRIMARY SCHOOL GIRLS' ATTENDANCE AND ACADEMIC PERFORMANCE IN THE DEMOCRATIC REPUBLIC OF THE CONGO (DRC)
}

\section{Jennifer Randall ${ }^{1}$}

University of Massachusetts Amherst, USA

\author{
Alejandra Garcia \\ University of Massachusetts Amherst, USA
}

\begin{abstract}
The Democratic Republic of the Congo continues to balance a commitment to education in general, and girls' education more specifically, and additional challenges brought about through cyclical conflict. The Valorisation de la Scholarisation de la Fille project aimed to improve literacy and numeracy by providing scholarships, tutoring, and comprehensive professional development for teachers. Using a randomized control design (RCT), we tracked both the achievement and attendance outcomes of these girls over a period of three years. Several factors positively influenced student growth in reading and mathematics, including the proportion of female teachers in the school, girls' perceptions of the school environment, receipt of a scholarship, and tutoring (math only). Household survey data suggest that the project minimized/reduced an already existing gap between enrollment in school for control and intervention communities; and school data suggest increased enrollment for girls in upper primary school. The findings suggest that programs designed to provide increased access to education may be the most successful in improving outcomes for students.
\end{abstract}

Keywords: Democratic Republic of the Congo, gender parity, literacy, numeracy, girls' education

\footnotetext{
${ }^{1}$ Correspondence: Jennifer Randall; College of Education; Furcolo Hall, 813 N. Pleasant St., Amherst, MA 01002; Email: jrandall@umass.edu
} 


\section{Introduction}

According to the United Nations (2018), 103 million youth do not have basic literacy skills. Although the number of primary-school aged children who are in school has been rising, currently, 57 million children in the developing world are still not enrolled in primary education (United Nations, 2018). Poverty, bureaucracy and corruption, war and armed conflict, lack of trained teachers, inadequate educational infrastructure and resources, and cultural beliefs around education continue to drive educational disparity in the most vulnerable countries (Rueckert, 2019). Education in the developing world continues to endure significant inequalities. Children from the poorest families are still much more likely to be out of school than children from the wealthiest families; and approximately $50 \%$ of out of school children live in conflict areas (United Nations, 2018).

Indeed, the presence of conflict can have catastrophic educational consequences. In 2015, an estimated 39 million children were out of school in conflict and emergency environments (UNICEF, 2016) and funding for education in emergencies has been declining in the recent years. Children living in countries impacted by conflict are $30 \%$ less likely to complete primary school and half as likely to complete lower-secondary school (International Commission on Financing Global Education Opportunity, 2016). Nevertheless, because governments tend to be overwhelmed attempting to provide the most critical needs such as food, clean water, and shelter, Education Cannot Wait, a global collaborative, estimates that only two percent of humanitarian funding is allocated specifically for education (Education Cannot Wait, 2020). Add to this, gender disparities tend to be exacerbated by conflict. Indeed, girls in conflict-affected countries are twice more likely to be out of school (UNESCO, 2015) as girls' education faces some unique challenges compared to boys' education.

These girl-specific challenges reflect social and institutional barriers which reflect historical marginalization, poverty, traditional gender roles, gender-biased curriculum and teaching practices, lack of facilities, discrimination in public institutions, and gender-based violence (Huggins \& Randell, 2007). Among the factors that contribute to girls' dropping out of school are early pregnancy, early marriage, lack of sanitary facilities, distance to school, pull of the labor market, and risk for abuse/in-school violence (Hunt, 2008; King \& Winthrop, 2015 ). Indeed, $48 \%$ of out-of-school girls are likely to never go to school, compared to $37 \%$ of boys (UNESCO, 2015).

It is within this context that we situate this study. The Valorisation de la Scholarisation de la Fille (VAS-Y-Fille) project - an initiative through the Girl's Education Challenge - sought to improve access to, and quality of, education for marginalized girls in the Democratic Republic of the Congo. We examined the impact of the scholarship and tutoring intervention components of this initiative on student learning and attendance outcomes. We begin with an overview of prior literature on the impact of similar intervention components (i.e. financial \& remediation) in the developing world. We then describe our intervention/study in detail and present our findings and recommendations.

\section{Financial Incentives (Scholarships) as Educational Interventions}

Research shows that household income plays an important role in girls' education, with poor girls being less likely to attend school (Hunt, 2008). In a study examining educational gender differences in a sample of families living in the Democratic Republic of the Congo (DRC), increased household income was associated with greater rates of enrollment and attainment (Shapiro \& Tambashe, 2001). Family costs to educating girls include direct fees, indirect fees, indirect costs, and opportunity costs. Girls' schooling can be made more affordable, and thus school enrollment can improve by reducing direct costs, 
covering indirect costs, and compensating opportunity costs through scholarships, stipends, school health and nutrition programs, and elimination of school fees (Herz \& Sperling, 2004). Schooling costs, direct or indirect, are a considerable factor in child school enrollment and attendance (Hunt, 2008). Families often incur costs even if education is free, thus further disadvantaging most destitute families. In most deprived groups, provision of schools and improvement of teaching quality needs to be supplemented by actions stimulating the demand for education and adaptation of services to communities' specific needs (Chimombo, 2005). Lowering school-related costs is one of the strategies in amending gender disparities in school enrollment and attainment.

Scholarships, fee waivers, and cash stipends are incentives that have been utilized to offset direct and indirect school costs for households in countries with low enrolment and completion of education in girls (see Kuepie et al., 2015; Lewis and Lockheed, 2007). Studies indicated that scholarship programs can reduce socio-economic gradients in school enrollment and attendance. As an encouraging example, in Bangladesh, scholarships increased girls' enrollment to twice the national average (Lewis \& Lockheed, 2007). Moreover, Filmer and Schady (2008) presented evidence of a scholarship program for poor girls in Cambodia that established that even when observable differences between recipients and non-recipients were controlled for, enrollment and attendance were 30 percentage points higher in girls who received scholarships and that girls with the lowest socioeconomic status showed larger impact. A merit-based scholarship program for primary school girls in two Kenyan districts was evaluated by Kremer and colleagues (2009) who found that the academic effects of the program were large, although the program was more successful in one district than the other. Still, other findings have been somewhat mixed. For example, in Cambodia, scholarships conditional on attendance and grade progression for girls transitioning from primary to secondary school helped increase girls' enrollment by $22 \%-32 \%$; however, in Nepal, scholarships failed to provide incentives for poor girls' families to send them to school, likely due to not covering all school costs sufficiently enough (United Nations, 2015).

\section{Remediation (Tutoring) as Educational Interventions}

Although there is a growing interest and use of a variety of remediation interventions (e.g. tutoring) to improve the outcomes of students in low and middle income nations, the formal research literature on the impact of these various remediation programs on the learning outcomes of students is less developed with inconclusive results. In a promising study, Banerjee, Cole, Duflo, and Linden (2007) investigated the impact of a remediation program in India in which primary school students were pulled from the regular classroom and tutored for half of the school day (approximately two hours). The authors found that the remediation program improved students' test scores by an average of .14 standard deviations in the first year and .28 standards by the end of year two. Interestingly, students in the bottom third of the test score distribution had the greatest gains with their test scores increasing by .40 standard deviations by the second year. No gains were found for control students. Followup analyses revealed that the gains remained, but at a much smaller magnitude a year after the intervention (to .10 standard deviations).

UNICEF's Getting Ready for School: A Child-to-Child Approach intervention (American Institutes for Research, 2013) was implemented in Bangladesh, the DRC, Ethiopia, Yemen and Tajikistan with less definitive results. Pre-Grade 1 students received tutoring from older students who were trained by teachers in an effort to improve their readiness/preparedness for school in a variety of content areas. Using both quasi-experimental and experimental evaluation approaches, results were mixed in that the peer-to-peer tutoring approach had a 
positive effect on overall reading/literacy in the DRC (Hedge's $g=.69$ ) and negative effect in Bangladesh (Hedge's $\mathrm{g}=-.24$ ). Specifically, students in the DRC demonstrated positive outcomes on specific literacy sub-skills including letter identification $(\mathrm{g}=.71)$ and writing $(\mathrm{g}$ $=.73$ ); and students in Bangladesh, alternatively, demonstrated negative outcomes on both the letter identification ( $\mathrm{g}=-.20)$ and beginning reading $(-.35)$ subtests; but showed positive outcomes $(\mathrm{g}=.28)$ with respect to writing. Changes in the overall reading scores of students in Ethiopia and Tajikistan were not meaningful, though students in Yemen showed positive outcomes on the letter identification subtest $(\mathrm{g}=.37)$.

Jayachandran (2014) also found evidence of negative outcomes related to tutoring programs. An investigation of the impact of afterschool tutoring services revealed that teachers in Nepal teach less during the regular school day. Indeed, teachers in schools with afterschool tutoring are 30\% less likely to teach the whole class period. Consequently, students (particularly those who did not reenroll in tutoring) performed more poorly on the secondary school national exam.

\section{Study Significance and Purpose}

Primary education enrollment in sub-Saharan Africa continues to lag behind most regions. Indeed, primary school enrollment is only moderate, which was at $78 \%$ in 2012. In addition, $56 \%$ of the countries that have not reached gender parity in primary education were in sub-Saharan Africa in 2012 (United Nations, 2015). Certainly, large-scale interventions have the potential to improve these educational outcomes of young children in any context. The impact of many popular intervention components as they relate specifically to education, however, has not been broadly established in conflict nations in general and the Democratic Republic of the Congo (DRC) specifically. Indeed, the need exists for randomized control trials (RCT) to evaluate both short-term and mid-term outcomes of global efforts for improving education for children in the developing world. This study seeks to fill that gap in the evaluation literature by investigating the impact of specific interventions on the learning and attendance/enrollment outcomes of in-school girls over a period of three years. Specifically, we addressed the following research questions:

1. What is the impact of tutoring on girls' literacy and numeracy outcomes (as measured by EGMA \& EGRA)?

2. What is the impact of scholarships on girls' literacy and numeracy outcomes (as measured by EGMA \& EGRA)?

3. What is the impact of scholarships on in-school girls' enrollment and attendance?

\section{Method}

\section{Setting: Democratic Republic of the Congo (DRC)}

In the DRC, a country located in the region of sub-Saharan Africa that is frequently and intermittently engaged in war and conflict, the total population comprised nearly 87 million people in 2019 up from just under 79 million in 2016. The DRC's GDP is still among the lowest in the world (Gladwell \& Tanner, 2014) with $76.6 \%$ of the population living on less than $\$ 1.90$ a day (World Data Atlas, 2012). In the DRC, an education attainment gap of approximately $20 \%$ exists between children born to poor families (15\%) and children in average households (35\%) (United Nations, 2015). As expected, gender parity, in terms of education attainment, also varies across economic status with the Gender Parity Index of the richest children in DRC rising from approximately .70 to .90 from 2000 to 2010 and decreasing with the poorest children from .55 to .70 (United Nations, 2015). Moreover, youth illiteracy in the DRC, defined as being unable to read and write with understanding a short 
simple statement on everyday life, is the second only to Bangladesh representing approximately 2.8 million youth in 2016 (World Data Atlas, 2016). UNICEF reported that the percentage of the population over 15 years of age who can read and write, was $79 \%$ for males and 53\% for females in 2012 (American Institutes for Research, 2013). According to 2012 UNICEF estimates, the war in the DRC resulted in the loss of three million lives, and a resurgence in conflict in 2008 resulted in massive displacements of the nation's citizens, with the number of displaced individuals in the eastern part of the DRC nearing 1.7 million in 2011 (Aker, 2014).

\section{The Intervention}

The Valorisation de la Scholarisation de la Fille (VAS-Y Fille!) - an initiative through the Girl's Education Challenge - targeted over 100,000 marginalized girls in primary and lower secondary schools in the Democratic Republic of the Congo. The goal of this initiative was to increase families' financial capacity to support girls' primary schooling; set up teacher training, tutoring, and community reading programs to improve girls' reading and mathematics skills; increase community involvement to ensure girls' access to education; and increase civil society engagement in providing alternative learning opportunities to allow girls not enrolled in school to complete primary school. The program included a comprehensive suite of interventions including a Social Empowerment (EA $\$ \mathrm{E}$ ) savings and loan program to help families build financial assets and maintain gains in education and a Literacy Boost community reading program.

Here, we focus on the two largest interventions - scholarships and tutoring. To aid girls in paying school fees, purchasing uniforms, and buying textbooks, VYF invested approximately 10.5 million USD to provide scholarships for over 75,000 girls. During the first academic year scholarships were provided based on need; however, in subsequent years all $5^{\text {th }}$ and $6^{\text {th }}$ grade girls in intervention schools received scholarships. To help girls improve their performance in mathematics and reading, approximately 129,000 girls in intervention schools in grades $3-6$ received tutoring in the form of 16 additional hours of instruction per week. VYF invested 3.9 million USD to train 7000 tutors, provide tutors with appropriate materials, and pay them a stipend. The tutoring intervention targeted the bottom $50 \%$ of the class based on academic performance, measured through standardized tests.

\section{Sampling Design}

A randomized control trial (RCT) was employed to evaluate the impact of the Vas-YFille! project. Random assignment occurred at the school cluster level. School clusters (212) were categorized by both province (Kasai, Province Orientale, Bandundu, Equateur, or Katanga) and subdivision (each province was composed of 2 to 9 subdivisions). To ensure representation across all five provinces and their subdivisions, a stratified random sampling technique was used. The data were first categorized/divided by province; then by subdivisions within each province. For Kasai Oriental, Province Orientale, Bandundu, and Equateur, approximately one-half of the school clusters within each subdivision were randomly selected to receive the intervention. Unselected school clusters were assigned to the control group. Students in the control group received no intervention (scholarships or tutoring) components. For Katanga, approximately $65 \%$ of the school clusters within each subdivision were randomly selected to receive the intervention.

Forty-three clusters were selected randomly in both treatment and control groups (86 clusters total). For each cluster, one school was selected randomly to be surveyed, or two when the number of girls in an individual school failed to meet the threshold. As a result (i.e., 
the need to include seven supplemental schools when the thresholds were not met in the original 86 schools), data were collected from girls in 93 schools.

Trained enumerators attempted to assess the same cohort of girls at subsequent data collection waves, but a replacement protocol had to be implemented due to attrition. Missing girls were replaced-by random selection-with new girls at each data collection wave. In addition, to ensure the intervention reached as many girls as possible, third grade girls were added/ eligible to receive intervention components in the $2^{\text {nd }}$ year of the intervention (Midline year). In other words, girls who were in the $2^{\text {nd }}$ grade at Baseline (Fall 2013) and Annual (Spring 2014) were enveloped into the study fall 2014-spring 2015 (Midline) when they entered the $3^{\text {rd }}$ grade. Moreover, girls were not tracked upon graduating from primary school. For example, girls in grade 6 at Baseline (2013) and Annual (2014) did not receive intervention components if they moved on to the $7^{\text {th }}$ grade and, consequently, were not included in Midline (2015) or Endline (2016) data collection waves.

\section{Measures}

\section{Literacy and Numeracy Outcome Measures (Tutoring)}

Early Grades Reading Assessment (EGRA). Children's literacy skills were assessed using the Early Grade Reading Assessment (EGRA; RTIa, 2009). Five subtests of the EGRA were used: Letter Recognition $(\alpha=.980)$, Invented Word Reading $(\alpha=.967)$, Oral Reading fluency $(\alpha=.987)$, Reading Comprehension $(\alpha=.787)$, and Oral Comprehension $(\alpha=.727)$. The EGRA takes about 15 minutes per child to administer, all of the subtests are orally administered, and some subtests are timed. The EGRA has been used in 31 different countries including DRC. To reflect the relative importance of each subtest (as determined by key stakeholders), the EGRA assessment score was calculated to weigh the sections in the following manner: Letter Recognition - 20\%, Invented Word Reading - 15\%, Words per Minute $-45 \%$, Reading Comprehension - 10\%, and Oral Comprehension - 10\%. To be sure all students understood the instructions, subtest instructions were translated into the relevant national languages (Kikongo, Lingala, Tshiluba, \& Swahili).

Early Grades Mathematics Assessment (EGMA). Children's math skills were tested using the Early Grade Mathematics Assessment (EGMA; RTIb, 2009). Five subtests were used: Reading/Recognizing Numbers $(\alpha=.940)$, Comparing Quantities $(\alpha=.861)$, Number Sequences Missing Values $(\alpha=.772)$, Addition $(\alpha=.911)$ and Subtraction $(\alpha=.925)$. Each subtest was weighed equally (.20). As with the EGRA, the EGMA takes about 15 minutes per child to administer, all of the subtests are orally administered, and some subtests are timed. To avoid the sharing and studying of test forms for both the EGRA and EGMA, new forms were developed for both the 2015 and 2016 administrations. Because different forms of a test may differ in difficulty, we used equating to ensure that the 2015 and 2016 forms were comparable to the 2013/2014 form.

\section{Enrollment and Attendance Outcome Measures (Scholarships)}

School Survey. School characteristics were collected through surveys administered to school directors during baseline data collection. The survey included questions such as number of children enrolled by grade and gender, primary language of instruction, number and gender breakdown of teachers, school resources, previous year (average) reading and mathematics achievement scores, and enrollment or attendance rates.

Household Survey. Community characteristics were collected through the oral administration of a Household Survey. Enumerators questioned the primary caregiver or head of household about the primary language spoken in the home, the number of adults and 
children in the home, the work responsibilities of the children in the home, financial concerns (related to school or other), household literacy, as well as prior and current school enrollment of children in the home.

\section{Sample}

At Baseline (2013), the average age of girls interviewed across the five provinces was 11.5 years $(\mathrm{SD}=2.0)$ with a minimum of 7 years and a maximum of 19 years. Kasai Orientale, Equateur, and Katanga had similar age distributions with means of 11.7 (SD = 1.9), 11.3 (SD $=2.1)$, and 11.6 $(\mathrm{SD}=2.0)$ years respectively, where Province Orientale had a slightly higher mean at 12.6 $(\mathrm{SD}=2.1$ ) years and Bandundu a slightly lower mean of $10.6(\mathrm{SD}=1.9)$ years. Girls reported a wide range of preferred languages at home including Swahili (25.9\%), Lingala (20.6\%), Tshiluba (23.8\%), and Kikongo (12\%). Only 1\% reported French as the preferred language at home. Most girls reported having extensive responsibilities outside of school including caring for other members of the family $(80.0 \%)$, cleaning or preparing meals (95.7\%), and working in the fields or outside of the home (49.6\%). In most cases the primary caregiver was the mother $(48.2 \%)$ or father $(34.7 \%)$ with fewer girls reporting a grandparent $(6.3 \%)$ or aunt/uncle $(4.7 \%)$ as the primary caregiver. Finally, the majority of the girls reported no visual (95.2\%), auditory (96.2\%), or mobility difficulties (97.3\%).

At Baseline, nearly all schools reported having both textbooks and at least one blackboard per classroom (95.7\%), being coeducational (95.7\%), and employing only full-time teachers (91.4\%). Schools met (were in-session) from 180 to 262 days the previous year with the majority of schools reporting 220 days of school; and $72 \%$ of schools reported a religious affiliation. Typically, schools followed governmental policy with respect to language of instruction as students tended to be taught in their local language (or bilingual instruction) in $1^{\text {st }}$ and $2^{\text {nd }}$ grades and in French-only beginning in the $3^{\text {rd }}$ grade.

\section{Data Collection}

The enumerator/surveyor trainings were facilitated by Monitoring \& Evaluation staff and trainers who were previously trained as trainers. Surveyors were trained for eight days to master tools and the procedure for administering EGRA/EGMA. Training included two practical days in the field. Surveyors were then deployed in teams with each team including one supervisor and an average of five to six surveyors. In addition to understanding the tools, a focus was put on the calculation of the attendance rate at schools and child protection. The data collection was carried out by surveyors recruited by the VYF project in September/October 2013 (Baseline), June 2014 (Annual), June 2015 (Midline) and June 2016 (Endline) in all five provinces in 93 evaluation schools and 86 communities.

\section{Data Analysis: Learning Outcomes}

In addition to examining basic descriptive information (mean scores over time), inferential methods were employed to determine if any casual relationships could be inferred, specifically hierarchical linear modeling (HLM). The use of HLM has two substantial benefits: (1) it allows for missing data at level one (time/test scores) so no students are removed from the overall analysis if they are missing one or more test scores; and (2) the nested nature of the data is accounted for in the parameter estimates. Moreover, the use of multi-level models allows for the inclusion, and more comprehensive interpretation, of multiple covariates.

The unconditional (no covariates) models are defined below: 
Equation 1

Level 1 (time): $\quad Y_{t i j}=\pi_{0 i j}+\pi_{1 i j}($ time $)+e_{t i j}$

Equation 2

Level 2 (student): $\quad \pi_{0 i j}=\beta_{00 j}+\beta_{01 j}\left(X_{i j}\right)+r_{0 i j}$

$\pi_{1 i j}=\beta_{10 j}+\beta_{11 j}\left(X_{i j}\right)+r_{1 i j}$

Equation 3

Level 3 (school): $\quad \beta_{00 j}=\gamma_{000}+\gamma_{001}\left(W_{i j}\right)+u_{00 j}$

$\beta_{10 j}=\gamma_{100}+\gamma_{101}\left(W_{i j}\right)+u_{10 j}$

Additionally, we included a conditional model to examine the impact of potential covariates (e.g. student attendance, classroom size, school resources) on student achievement. Covariates were selected based on previous literature/research on learning models, the theory of change, and in-field observations. These covariates were examined in an attempt to provide additional context to the results as they relate to achievement outcomes. The covariates considered at level-2 (student) were: variables related to the home (a) whether the girl works most of the day and (b) whether the school language is the same as the girl's home language; related to school (a) the girl's perception of her teacher and (b) the girl's perception of the schools' social environment; as well as the intervention variables (a) whether the girl received a scholarship (in $2014 \&$ in 2015 ) and (b) whether the girl received tutoring (in each school year). The variables considered at level-3 (school) were (a) whether the school was an intervention school, (b) the percent of female teachers at the school, and (c) the region where the school was located (Province Orientale, Kasai Oriental, Bandundu, Equateur, \& Katanga).

We used the interclass correlation (ICC) to determine the variance explain by our reading and math models. The ICC is a recommended manner of understanding effect size in HLM models and is calculated with the following equation (Raudenbush \& Bryk, 2002):

$$
\frac{\tau_{00 \beta}}{\tau_{00 \beta}+\tau_{00 \pi}}
$$

\section{Data Analysis: Enrollment and Attendance Outcomes}

Although learning outcome data (i.e. EGMA \& EGRA scores) were collected at the student-level in that we tracked the scores of randomly selected individual students (whenever possible), attendance and enrollment data were collected at the aggregate level. We (a) examined the attendance registers of evaluation schools to determine the aggregate numbers of students present; (b) conducted unannounced spot checks of attendance registers to ensure fidelity; and (c) surveyed households to determine enrollment rates over the course of the intervention.

\section{Results}

Below we present the findings beginning with learning outcomes (reading and mathematics). Basic descriptive data/trends (mean, standard deviation, and sample size) are discussed followed by the results of the multi-level analysis (in which we control for a variety of variables as outlined in the method). In the last section of the results, we present the findings as they relate to student attendance and enrollment based on data collected from school rosters, household surveys, and evaluator/enumerator spot checks. 


\section{Reading Outcomes}

Figure 1 displays mean EGRA scores for the full sample of in-school girls in the control and intervention conditions across time. The intervention group had consistently higher scores than the control group, and this difference in scores steadily increased from Baseline (2013) to Endline (2016).

Figure 1.

Mean EGRA Scores (in \%) for Baseline, Annual, Midline, and Endline, by Condition

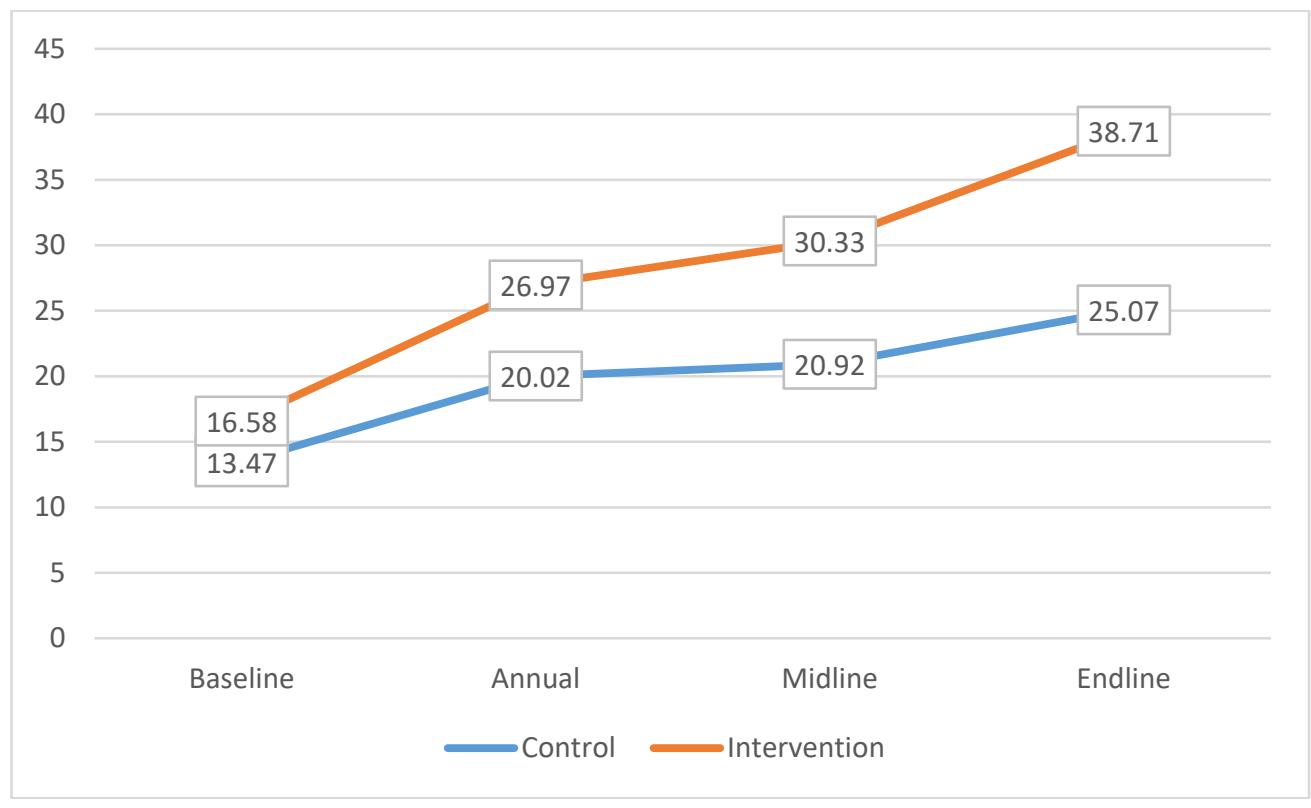

The results from the multi-level modeling analysis provide a more fine-grain view of the intervention's impact. When controlling for all other variables (home \& school related), the predicted EGRA percent score growth for girls attending an intervention school increases by 1.81 percentage points. In addition, we found that several covariates influenced the overall EGRA score predictions of girls. Specifically, (a) 10\% increase in the percentage of female teachers in a school resulted in a predicted increase in the EGRA score growth of 0.47 percentage points; (b) as a girl's perception of her school's social environment became more positive by one unit in 2015, her predicted EGRA percent score growth increased by 0.86 percentage points; (c) whether a girl received a scholarship in 2015 increased her predicted EGRA percent score growth by 2.49 percentage points; and (d) whether a girl received a scholarship in 2016 increased her predicted EGRA percent score growth by 3.32 percentage points. Based on the ICC, the final model explained $27.2 \%$ of the between-school variance.

These results suggest that several contextual factors influenced student growth in literacy between October 2013 and May 2016. Most noticeably, receipt of a scholarship in 2016 (a very specific component of the project's total intervention) resulted in the highest rate of predicted growth overall (over three percentage points). Nonetheless, several variables/characteristics, perhaps unexpectedly, failed to have any impact in the predicted growth rate in student scores - most notably, the work requirements of girls outside of school and the receipt of additional tutoring. 


\section{Mathematics Outcomes}

Figure 2 displays mean EGMA scores for the full sample of in-school girls in the control and intervention conditions across time. Even though the average scores of girls in the intervention group decreased by approximately two points between Annual and Midline, it increased again between Midline and Endline. Furthermore, the intervention group had consistently higher scores than the control group since Baseline, and the difference between the two conditions became more pronounced at Endline.

As with the EGRA analysis, a multi-level model was used to analyze the EGMA scores investigating identical covariates to illuminate any possible contextual influences on student performance and/or growth. These results highlight the main findings. When controlling for all other variables, the predicted EGMA percent score growth for girls attending an intervention school increases by 2.31 percentage points. In addition, we found that (a) the predicted EGMA score growth for girls attending a school in the Province Orientale region decreased by 5.12 units; (b) whether a girl worked more than four hours a day in 2016 decreased her predicted EGMA score growth by 0.90 units; (c) whether a girl received tutoring in 2016 increased her predicted EGMA score growth by 1.04 units; and (d) whether a girl received a scholarship in 2015 decreased her predicted EGMA percent score growth by 2.42 percentage points. Unlike the results with respect to growth in literacy outcomes, the percent of female teachers and the girl's perception of her school's social environment were not significant when included in the model with all other covariates when measuring growth in mathematics performance. Based on the ICC, the final model explained $29.2 \%$ of the between-school variance.

\section{Figure 2.}

Mean EGMA Scores (in \%) for Baseline, Annual, Midline, and Endline, by Condition

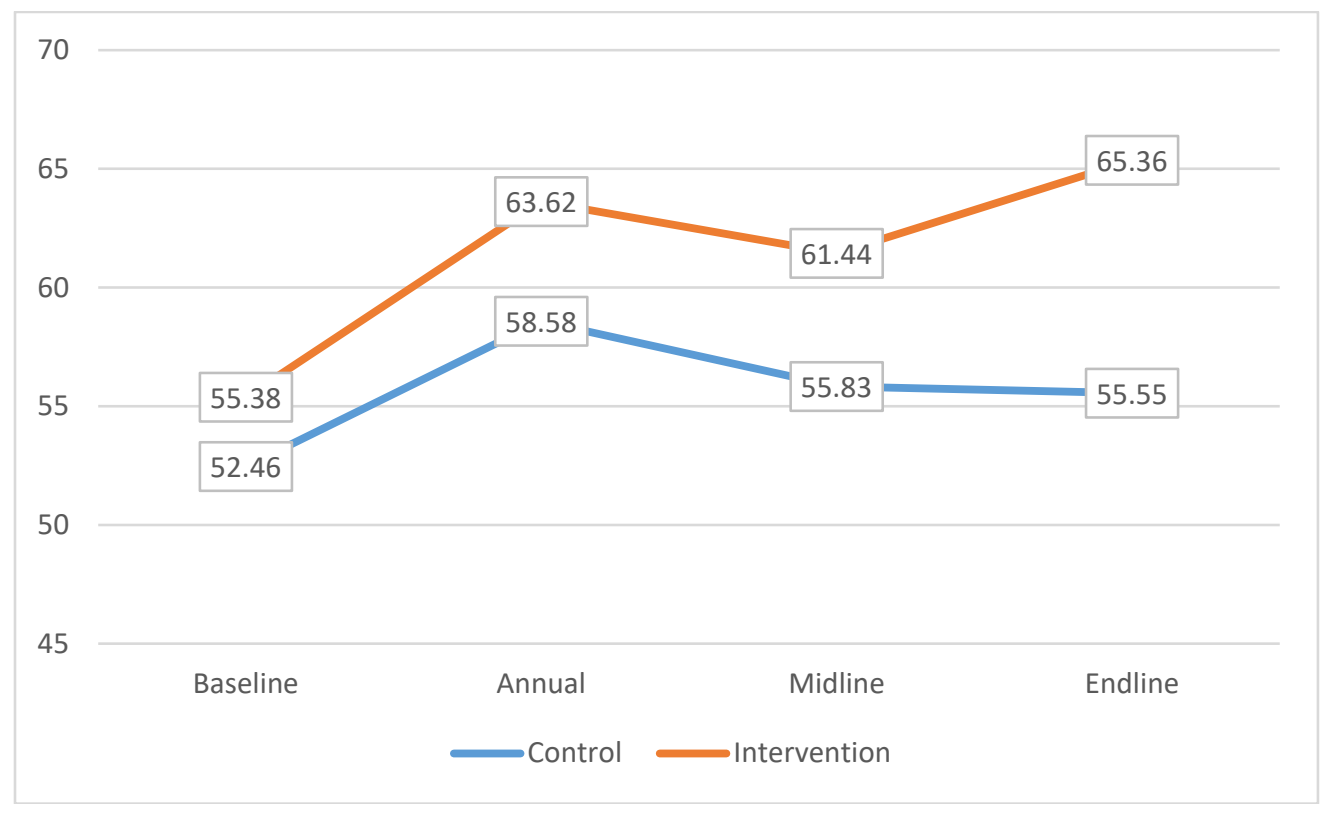




\section{Attendance Outcomes}

Table 1 shows the attendance rates of cohorts of students at both Baseline and Endline $^{2}$. Readers should note a considerable increase in the attendance rates of girls from 2013 to 2016. Indeed, girls enrolled in intervention schools improved their attendance rate by more than 10\% (10.3\% for Grade 2, 10.6\% for Grade 3 Baseline cohort and 11.2\% for Grade 4 Baseline cohort); whereas girls enrolled in control schools showed an increase ranging from $3.0-4.1 \%$.

Table 1.

Attendance Based on School Registers - Comparison of Intervention and Control Schools

\begin{tabular}{llcccccc} 
& & \multicolumn{2}{c}{ Baseline } & \multicolumn{2}{c}{ Endline } & \multicolumn{2}{c}{ Difference } \\
\cline { 3 - 7 } Grade at & Grade at & & & & & \\
Baseline & Endline & Control & Interv. & Control & Interv. & Control & Interv. \\
\hline Grade 2 & Grade 4 & $75.5 \%$ & $72.7 \%$ & $79.6 \%$ & $83.0 \%$ & 4.1 & 10.3 \\
Grade 3 & Grade 5 & $75.7 \%$ & $76.1 \%$ & $79.4 \%$ & $86.7 \%$ & 3.7 & 10.6 \\
Grade 4 & Grade 6 & $77.4 \%$ & $77.7 \%$ & $80.4 \%$ & $88.9 \%$ & 3.0 & 11.2 \\
\hline
\end{tabular}

Table 2.

Endline Spotchecks by Current Grade Level

\begin{tabular}{ccccc} 
& \multicolumn{2}{c}{$\begin{array}{c}\text { \% Girl Registered } \\
\text { Recorded }\end{array}$} & \multicolumn{2}{c}{$\begin{array}{c}\text { \% Girl Registered } \\
\text { Physically Present }\end{array}$} \\
\cline { 2 - 5 } & Intervention & Control & Intervention & Control \\
\hline Grade 3 & 85.21 & 79.71 & 69.62 & 73.56 \\
Grade 4 & 83.11 & 81.02 & 84.10 & 85.21 \\
Grade 5 & 85.99 & 82.51 & 80.04 & 80.43 \\
Grade 6 & 87.93 & 78.37 & 66.08 & 62.15 \\
\hline
\end{tabular}

In addition to attendance data gathered from school registers in evaluation communities, unannounced spot checks were conducted at 47 schools by the external evaluators to validate the school attendance data collected in the school registers. Table 2 includes the findings of the spot checks. Overall, in intervention schools the proportion of girls recorded as present was noticeably higher than the proportion of girls actually present. Specifically, although the registers indicated that nearly $78.5 \%$ of girls were present in school the day of the unannounced spot checks, evaluators found only $65.42 \%$ present. We did find, however, a smaller discrepancy between the proportion of girls actually present and those recorded as present in control schools.

Figure 3 allows the reader to examine attendance patterns between Midline and Endline data collections as indicated by the data gathered during the spot checks (from the enumerators and external evaluators). Although the figures reveal similar observed

\footnotetext{
${ }^{2}$ The reader will notice that no midline attendance data is provided in this section of the report. Indeed, the project faced a major challenge with attendance data at midline. First, registers in the field were not always available and sometimes non-existent. Teachers in different provinces calculated attendance differently in registers. As a consequence, when the enumerators collected the attendance data, some were confused, which resulted in different calculations in different sites. Consequently, calculations were found not to be comparable over the various provinces and we were unable to use midline attendance data.
} 
attendance rates at Endline for both intervention and control schools, the growth trajectory for intervention schools is considerably steeper suggesting the project had a positive impact on attendance.

Figure 3.

Attendance as Indicated by Spot Checks

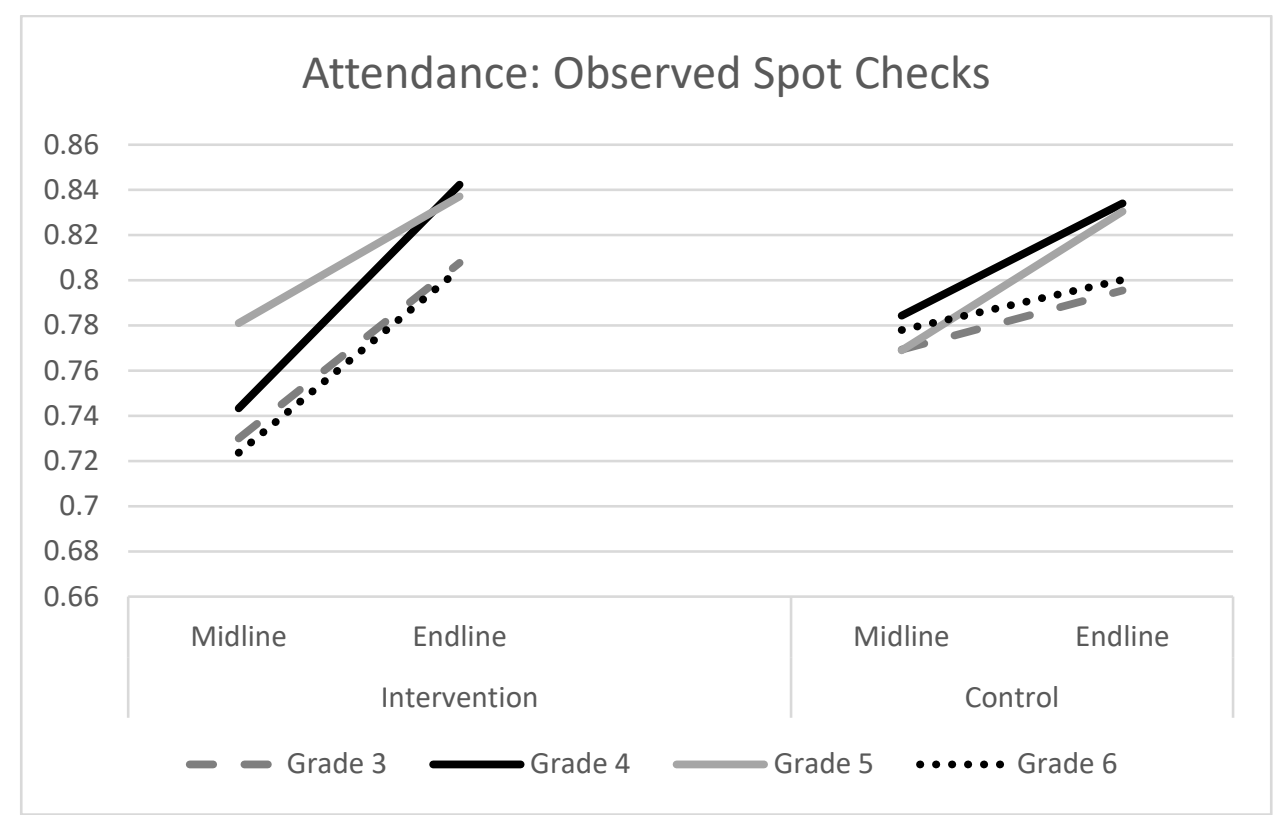

\section{Enrollment}

In addition to attendance rates, we examined enrollment rates over the course of the intervention. Recall that these data were collected through household surveys in intervention and control communities. Table 3 displays the mean percent of girls declared as enrolled in a traditional school or Accelerated Learning Program by the households. Results show that enrollment declined slightly in 2014 and 2015 for girls, but increased slightly when data were collected at Endline (from $79.39 \%$ at midline to $80.11 \%$ at Endline) in intervention schools; while continuing to decline slightly (not practically significant) for control schools. School enrollment was also tracked via school registers. As seen in Table 3, in control schools the mean number of girls enrolled decreased between midline (2015) and Endline (2016) across all grade levels whereas mean enrollment in intervention schools increased for girls across all grade levels.

\section{Discussion}

In this study, we investigated the achievement and attendance outcomes of girls in the DRC over a period of three years using a randomized control design. Our findings with respect to reading outcomes suggest that - though being in an intervention school resulted in greater growth in reading scores overall - several contextual factors influenced student growth in literacy (reading) between October 2013 and May 2016 (including the proportion of female teachers in the school, and girls' perceptions of the school environment). Most noticeably, however, receipt of a scholarship in 2016 (a very specific component of the project's total intervention) resulted in the highest rate of growth overall (over three percentage points). 
Table 3.

Mean Number of Girls Enrolled in School per Grade by Condition

\begin{tabular}{lcccccc} 
& \multicolumn{3}{c}{ Control } & \multicolumn{3}{c}{ Intervention } \\
\cline { 2 - 6 } Cohort at Baseline & Annual & Midline & Endline & Annual & Midline & Endline \\
\hline Grade 2 & 39.39 & 37.15 & 35.46 & 40.23 & 39.57 & 40.98 \\
Grade 3 & 36.2 & 33.37 & 30.46 & 35.85 & 42.87 & 47.70 \\
Grade 4 & 26.48 & 25.46 & 24.33 & 28.4 & 33.43 & 38.34 \\
\hline
\end{tabular}

Interestingly, (when controlling for other variables), the use of a tutor had no statistically significant impact on girls' reading scores. This finding may simply reflect the magnitude of the other components of the intervention than the impact of tutoring itself. Indeed, tuition-free, girl-friendly (e.g. female teachers) environments encourage school attendance which, in turn, is likely to lead to greater learning outcomes. An alternative explanation can be, unfortunately, one of the unintended consequences that are often revealed with large scale interventions. Several enumerators noticed that some girls who did not receive scholarships (but did receive tutoring) opted not to attend regular classes but did participate in the free after-school tutoring component. Consequently, tutoring did not, indeed, increase the net gain in instructional hours for many girls. It is conceivable that the end result would be that for many girls tutoring simply "cancelled out" their lack of school attendance.

With respect to mathematics, similar to reading growth, being enrolled in an intervention school resulted in greater growth in mathematics achievement as measured by the EGMA. Indeed, the achievement gap between students enrolled in control and intervention schools widened over the duration of the intervention (i.e. girls enrolled in control schools grew by approximately 3\%; whereas girls in intervention schools grew by nearly $10 \%$ ). Still, some interesting findings were revealed. Unlike with reading, receiving mathematics tutoring during the last year of the intervention resulted in a modest increase in predicted EGMA score growth (1.04\%); but receiving a scholarship during the second year actually resulted in a decrease in predicted growth $(2.42 \%)$.

\section{Enrollment/Attendance}

A major component of the project's intervention was the delivery of scholarships to students to remove some part of the financial barrier to school access. The data from school administrators suggests that the project was moderately successful in this regard. In intervention schools, the mean number of girls enrolled in school increased for Cohort/Grade 2, 3, and 4 girls over the duration of the project. In control schools, however, girls' enrollment in these same grades decreased over time. Indeed, when queried with respect to the reasons for girls' lack of enrollment, a variety of reasons not directly related to financial barriers were provided including pregnancy, illness, and distance (see Table 4). This finding is not surprising and is congruent with other research. A review conducted by Holla and Kremer (2008) summarized the lessons from health and education evaluations conducted in the developing countries. Interventions specific to education included provision of school uniforms, conditional cash transfers, school meals, and girls' scholarship programs, all showed positive effects on girls' school attendance and dropout rates (Holla \& Kremer, 2008).

The data from the household survey, however, represent a different, perhaps unexpected, narrative. Indeed, it suggests that the project failed to increase girl enrollment 
in schools. We see a steady decline in the proportion of girls enrolled in school from Baseline $(85.99 \%)$ to Endline $(80.11 \%)$ in intervention communities; and a similar pattern between Baseline $(87.58 \%)$ and Endline $(80.68 \%)$ for control communities. Interestingly, at the project's onset (2013) student enrollment in control communities was nearly $1.6 \%$ higher than enrollment in intervention communities. Though both communities reported lower enrollment rates for girls in their homes, the gap between intervention and control communities decreased to $0.57 \%$ at Endline. We argue that (at worst) the project minimized/reduced an already existing gap between enrollment in school for control and intervention communities (as indicated by household data) and (at best) actually increased enrollment for girls in upper primary school (according to school data).

Table 4.

Reasons Why Girls Stopped Going to School

\begin{tabular}{lcc} 
Reason provided & Frequency & Percent \\
\hline Her family does not have the money for school & 80 & $30.1 \%$ \\
She switched schools & 49 & $18.4 \%$ \\
Could not pay school fees & 17 & $6.4 \%$ \\
A family member has died & 14 & $5.3 \%$ \\
She is pregnant / has had a child & 11 & $4.1 \%$ \\
She lives too far & 10 & $3.8 \%$ \\
She is sick & 8 & $3 \%$ \\
\hline
\end{tabular}

Attendance trajectories - as reported by school registers - suggest more positive outcomes. Baseline Grade 3 and Grade 4 cohorts saw increases in attendance rates in both control and intervention schools. In control schools, the cohorts of girls experienced a $3.7 \%$ $\left(3^{\text {rd }}\right)$ and $3.0 \%\left(4^{\text {th }}\right)$ increase in attendance rates from Baseline to Endline. In intervention schools, the cohorts experienced an even larger increase in attendance rates for both the baseline third grade cohort (10.6\%) and fourth grade cohort (11.2\%). Still, we must also acknowledge the considerable discrepancies found between the intervention school registers and the records of the enumerators with schools reporting more girls present than were actually in attendance. Although we can only speculate as to the reason(s) for these discrepancies, it is possible that administrators in intervention schools felt pressure (perhaps self-imposed) to "improve" the attendance records so that they could continue to receive project support. Also, it should be noted that some of the spot checks were conducted late in the school year at exam time, which might have influenced record keeping.

\section{Conclusions and Recommendations}

Implementing research in contexts like the DRC often involves challenges that influence the research design, analysis, or interpretation of results. The most serious limitation we faced throughout the duration of the project was attrition - in both locating/tracking participants and identifying the reasons for the inability to participate in follow-up interviews. A replacement protocol was implemented to maintain an adequate sample size.

The VYF services led to many positive results in intervention schools but possibly had adverse effects in both control and non-intervention schools. For example, some students left non-intervention schools to go to intervention schools; and many enumerators had difficulties in obtaining data from the control group because the former were not welcome by 
the local administration officers and school head-teachers. Future projects should stratify schools by location clusters (not simply by school clusters) to avoid having intervention and control schools too close together. In this way, control schools will feel less discouraged/resentful of intervention schools and relocating to an intervention school (from a control school) will be less likely. In addition, and most importantly, projects should provide some minimum - yet meaningful - services to the control group (e.g., provision of school supplies and teacher training after the Endline) to thwart feelings of resentment.

Our findings with respect to scholarships echo those of many other studies of financial incentives - scholarships have a positive impact on student learning. Given this evidence, we call into the question the appropriateness of the inclusion of scholarships as a primary component to be evaluated in future projects. In the case of the VYF project, multi-level results indicate that scholarships had the greatest impact on student learning (note: tutoring was not a significant predictor of growth at all for reading and less significant for math). Moving forward, donors should assume that providing students with scholarships increases their chances for success. This success is likely due to the fact that scholarships allow them to attend school; and children who attend school learn more. Having this information, providing scholarships to girls in intervention schools only is of little research value at best and unethical at worst. We recommend that future RCT of this nature provide scholarships to all students (in both control and intervention schools). Doing so addresses two issues: (1) students and administrators in control schools are not demoralized by having to participate in an on-going study without any hope of compensation and (2) as scholarships are intended to increase attendance, attendance would be increased (equalized) across both intervention and control schools allowing projects to evaluate the impact of the project's other components - especially remediation interventions - intended to address learning outcomes directly.

Our final recommendation relates to teacher - as opposed to student - remediation. The VYF project provided valuable teacher training related to teaching methods and positive disciplining methods. Some teachers, however, had a very low education level from the start and could not make sufficient progress, especially in math. This problem may also partially explain the lower-than-expected Early Grade Reading and Math Assessments (EGRAEGMA) results in some of the intervention schools. There is a need to engage in both policy dialogue and direct action in the field to try to address the issue (e.g., long-term training for teachers is often needed). However, any such long-term training needs to be accompanied with trainees' commitment to continue teaching over a period in the future, as well-trained teachers have a tendency to seek alternative employment, e.g., in local or international NGOs.

We hope, at a minimum, our findings will generate more thoughtful and researchinformed discussions and decisions on improving the learning outcomes and, consequently, life outcomes of girls in low-income, post-conflict countries.

\section{References}

Aker, J. C. (2014). Comparing cash and voucher transfers in a humanitarian context: Evidence from the Democratic Republic of the Congo. Retrieved from http://sites.tufts.edu/jennyaker/files/2010/02/Cash_versus_Vouchers_1sept2014. pdf

American Institutes for Research. (2013). Getting Ready for School: A Child-to-Child Approach: Program evaluation report. http://www.childtochild.org.uk/wpcontent/uploads/2014/07/AIR-Report-of-Child-to-Child-Pilot-Findings_June_2013 A4.pdf 
Banerjee, A., Cole, S., Duflo, E., \& Linden, L. (2007). Remedying education: Evidence from two randomized experiments in India. The Quarterly Journal of Economics, 122 (3)1235-1264. https://doi.org/10.3386/w 11904

Chimombo, J. P. (2005). Issues in basic education in developing countries: An exploration of policy options for improved delivery. Journal of International Cooperation in Education, 8(1), 129-152. https://doi.org/10.1086/533548

Education Cannot Wait. (2020). The situation. Retrieved July 31, 2020, from https://www.educationcannotwait.org/the-situation/

Filmer, D., \& Schady, N. (2008). Getting girls into school: Evidence from a scholarship program in Cambodia. Economic Development and Cultural Change, 56(3), 581-617.

Gladwell, C., \& Tanner, L. (2004). Hear it from the children: Why education in emergencies is critical. Save the Children UK. https://inee.org/system/files/resources/Hear_it_from_the_children.pdf

Herz, B., \& Sperling, G. (2004). What works in girls' education; Evidence and policies from the developing world. Council on Foreign Relations. https://www.cfr.org/content/publications/attachments/Girls_Education_full.pdf

Holla, A. \& Kremer, M. (2008). Pricing and access: Lessons from randomized evaluations in education and health (Working Paper No. 158). Center for Global Development. https://doi.org/10.2139/ssrn.1390281

Huggins, Allison \& Randell, Shirley. (2007). Gender equality in education in Rwanda: What is happening to our girls? Paper presented at the South African Association of Women Graduates Conference on "Drop-outs from School and Tertiary Studies: What is Happening to our Girls?" Capetown, May, 2007.

Hunt, F. (2008). Dropping out from school: A cross country review of literature. Project Report. Consortium for Research on Educational Access, Transitions and Equity (CREATE), Falmer, UK.

Jayachandran, S. (2014). Incentives to teach badly: After-school tutoring in developing countries. Journal of Development Economics, 108, 190-205. https://doi.org/10.1016/j.jdeveco.2014.02.008

King, W. \& Winthrop, R. (2015). Today's challenges for girls' education (Global Economy and Development at Brookings Working Paper No. 90). Retrieved July 31, 2020, from https://www.brookings.edu/wp-content/uploads/2016/07/Todays-ChallengesGirls-Educationv6.pdf.

Kremer, M., Miguel, E., \& Thornton, R. (2009). Incentives to learn. The Review of Economics and Statistics, 91(3), 437-456. https://doi.org/10.1162/rest.91.3.437

Kuepie, M., Shapiro, D., \& Tenikue, M. (2015). Access to schooling and staying in school in Sub-Saharan Africa. African Development Review 27(4), 403-414. https://doi.org/10.1111/1467-8268.12156

Lewis, M. A., \& Lockheed, M. E. (2007). Getting all girls into school. Finance and Development, 44(2), 17.

Raudenbush, S.W., \& Bryk, A.S. (2002). Hierarchical linear models: Applications and data analysis methods. Sage Publications, Inc.

RTI International. (2009a). Early Grade Reading Assessment toolkit. Prepared for the World Bank, Office of Human Development, under Contract No. 7141961. Retrieved from https://s3.amazonaws.com/inee- assets/resources/EGRA_Toolkit_Maro9.pdf

RTI International. (2009b). Early Grade Mathematics Assessment (EGMA): A conceptual framework based on mathematics skills development in children. Prepared under the USAID Education Data for Decision Making (EdData II) project, Task Order No. 
EHC-E-02-04-00004-00. Retrieved from https://pdf.usaid.gov/pdf_docs/Pnads439.pdf

Rueckert, P. (2019, August 13). 10 Barriers to Education That Children Living in Poverty Face. Global Citizen. https://www.globalcitizen.org/en/content/10-barriers-toeducation-around-the-world-2/

Shapiro, D., \& Tambashe, B. O. (2001). Gender, poverty, family structure, and investments in children's education in Kinshasa, Congo. Economics of Education Review, 20(4), 359-375. https://doi.org/10.1016/S0272-7757(00)00059-5

UNESCO (2015). Gender and EFA 2000-2015: Achievements and Challenges. Education For All Global Monitoring Report. Retrieved October 16, 2020, from https:// unesdoc.unesco.org/ark:/48223/pfo000234809

UNICEF. (2016). Education cannot wait: A fund for education in emergencies. https://www.unicef.org.uk/publications/education-cannot-wait/

United Nations (2015). The Millennium Development Goals Report. Retrieved from http://www.un.org/millenniumgoals

United Nations. (2018). Sustainable development goals. Retrieved July 3 1, 2020, from https://www.un.org/sustainabledevelopment/sustainable-development-goals/

World Data Atlas (2012). Democratic Republic of the Congo Economy. Retrieved October 16, 2020, from https://knoema.com/atlas/Democratic-Republic-of-theCongo/Poverty-rate

World Data Atlas (2016). Democratic Republic of the Congo Education. Retrieved October 16, 2020, from https://knoema.com/atlas/Democratic-Republic-of-the-Congo/Youth-literacyrate

\section{About the Authors}

Jennifer Randall is an associate professor in the Research, Educational Measurement, and Psychometrics program and Director of Evaluation Services for the Center for Educational Assessment at the University of Massachusetts, Amherst (USA). Her research interests center around the impact of small and large scale assessments on historically marginalized students.

Alejandra Garcia is a doctoral candidate in the Research, Educational Measurement, and Psychometrics program and graduate research associate for the Center for Educational Assessment at the University of Massachusetts, Amherst (USA). 